\title{
Hematological manifestations and complications of COVID-19
}

\author{
Burak Erdinc ${ }^{1, A-D}$, Sonu Sahni, ${ }^{1, E, F}$, Vladimir Gotlieb ${ }^{2, E, F}$ \\ ${ }^{1}$ Department of Internal Medicine, Brookdale University Hospital and Medical Center, New York, USA \\ ${ }^{2}$ Department of Hematology and Oncology, Brookdale University Hospital and Medical Center, New York, USA \\ A - research concept and design; B - collection and/or assembly of data; $C$ - data analysis and interpretation; \\ $D$ - writing the article; $E$ - critical revision of the article; $F$ - final approval of the article
}

\section{Address for correspondence \\ Burak Erdinc}

E-mail: berdincmd@gmail.com

\section{Funding sources}

None declared

\section{Conflict of interest}

None declared

Received on August 31, 2020

Reviewed on October 28, 2020

Accepted on November 18, 2020

\begin{abstract}
The virus SARS-CoV-2 commonly causes self-resolving, flu-like illnesses in the majority of patients, but a critical illness can be seen in 5\% of cases - especially in the elderly population or in patients with multiple comorbidities. When COVID-19 is severe, it can cause pneumonia and hypoxemic respiratory failure, and can progress to viremia involving multiple organ systems. It causes significant cytopenia, mainly severe lymphopenia, and excessive exhaustion of CD8 + T cells, resulting in an immunocompromised state and cytokine storm. Furthermore, COVID-19 can commonly be complicated with acute thrombotic events, including venous thromboembolism, acute stroke, acute myocardial infarction, clotting of hemodialysis and extracorporeal membrane oxygenation (ECMO) catheters, and acute limb ischemia. This makes SARS-COV-2 a unique virus with an undiscovered pathophysiology. Therefore, patients with COVID-19 need close monitoring of their symptoms and laboratory parameters, and early hospitalization and treatment in severe cases. Early identification of severe cases and the abovementioned complications of COVID-19 could decrease the morbidity and mortality caused by the disease. In the study, we summarize what is currently known about the hematological manifestations and complications of COVID-19.
\end{abstract}

Key words: COVID-19, lymphopenia, cytokine storm, thromboembolism, hypercoagulable state

Cite as

Erdinc B, Sahni S, Gotlieb V. Hematological manifestations and complications of COVID-19. Adv Clin Exp Med. 2021;30(1):101-107. doi:10.17219/acem/130604

DOI

10.17219/acem/130604

\section{Copyright}

Copyright by Author(s)

This is an article distributed under the terms of the

Creative Commons Attribution 3.0 Unported (CC BY 3.0)

(https://creativecommons.org/licenses/by/3.0/) 


\section{Introduction and background}

The coronavirus disease from 2019 (COVID-19), which is caused by severe acute respiratory syndrome coronavirus 2 (SARS-CoV-2), has infected more than 16 million people and killed more than 650,000 around the world., ${ }^{1,2}$ It was first identified in Wuhan, China at the end of 2019 and rapidly spread, resulting in a pandemic. Coronaviruses are enveloped RNA viruses which commonly cause coldlike illnesses in immunocompetent hosts. ${ }^{3}$ It has a similar receptor binding structure to that of the SARS-CoV virus and uses angiotensin-converting enzyme 2 (ACE2) to enter the host cells. ${ }^{4}$ SARS-CoV-2 is mainly transmitted person to person via close contact or droplets with an incubation period - on average 5 days prior to symptoms appearing. ${ }^{5}$ It causes life-threatening disease in $5 \%$ of cases, especially in the elderly and in patients with multiple coexisting medical conditions; it has a mortality rate of $2.3 \%{ }^{6}$ Previously detected strains, the severe acute respiratory syndrome coronavirus (SARS-CoV) and Middle East respiratory syndrome coronavirus (MERS-CoV), are zoonotic viruses which caused outbreaks in China and the Middle East, respectively. However, they did not result in a pandemic such as SARS-CoV-2 has. ${ }^{7-9}$ COVID-19 primarily manifests as a respiratory tract infection causing hypoxemic respiratory failure. However, there is an enormous amount of data published almost daily demonstrating that it may involve multiple organ systems, including the nervous, cardiovascular, respiratory, gastrointestinal, renal, hematopoietic, and immune systems. This article summarizes the hematological manifestations and complications of COVID-19.

\section{Alterations in cell counts in COVID-19}

One of the first hematological manifestations of COVID-19 to be noticed was alterations in cell lineages, lymphopenia being the most prominent finding. A summary of tables examining cell lineage alterations in COVID-19 is presented in Table 1 . A retrospective observation of 7,736 patients in China during the first 2 months of the pandemic outbreak compared the clinical characteristics of patients between severe and non-severe cases. ${ }^{10}$ Guan et al. found that the majority of the patients had low blood counts across all lineages, which were more prominent in patients with a severe form of the disease. ${ }^{10} \mathrm{On}$ admission, lymphopenia was present in $83.2 \%$ of the patients, thrombocytopenia in $36.2 \%$ and leukopenia in $33.7 \%$. Lymphopenia was the most commonly seen abnormally in blood counts, being present in $96 \%$ of the severe cases and $80 \%$ of the non-severe cases. The median hemoglobin level was found to be lower in severe cases than in nonsevere cases $(12.8 \mathrm{~g} / \mathrm{dL}$ and $13.5 \mathrm{~g} / \mathrm{dL}$, respectively). In addition, thrombocytopenia was seen in $57.7 \%$ of the severe cases and in $31.6 \%$ of the non-severe cases. Other observational studies from China with fewer patients (41, 99, 138, and 201) reported similar results on patients with COVID-19: lymphopenia was evident in all studies and was more commonly seen in severe cases. ${ }^{11-13}$ A retrospective cohort study with 201 patients from Wuhan focused on a comparison of patients with acute respiratory distress syndrome (ARDS) with those without ARDS. They found that the patients with ARDS had significantly lower lymphocyte counts and CD-8 T-cell counts. The study also showed that patients with neutrophilia had an increased risk of mortality. ${ }^{13}$ This might be secondary to the disease course becoming complicated by bacterial superinfection. Further studies from other countries

Table 1. Alterations in cell counts in COVID-19

\begin{tabular}{|c|c|c|c|c|c|c|c|c|}
\hline Study & $\begin{array}{c}\text { Patient } \\
\text { population }\end{array}$ & $\begin{array}{l}\text { WBC, median } \\
{\left[10^{3} / \mu \mathrm{L}\right]}\end{array}$ & Leukopenia & $\begin{array}{c}\text { ALC, median } \\
{\left[10^{3} / \mu \mathrm{L}\right]}\end{array}$ & Lymphopenia & $\begin{array}{c}\text { Hgb, } \\
\text { median } \\
{[\mathrm{g} / \mathrm{dL}]}\end{array}$ & $\begin{array}{l}\text { Platelets } \\
{\left[10^{3} / \mu \mathrm{L}\right]}\end{array}$ & Thrombocytopenia \\
\hline $\begin{array}{l}\text { Guan } \\
\text { et al. }{ }^{10}\end{array}$ & $\begin{array}{c}1099 \text { hospitalized } \\
\text { patients }\end{array}$ & 4700 & $33.7 \%$ & 1000 & $83.2 \%$ & 13.4 & 168 & $36.2 \%$ \\
\hline $\begin{array}{l}\text { Wu } \\
\text { et al. }{ }^{13}\end{array}$ & $\begin{array}{c}201 \text { hospitalized } \\
\text { patients }\end{array}$ & 5940 & $\mathrm{~N} / \mathrm{A}$ & 910 & $64 \%$ & $\mathrm{~N} / \mathrm{A}$ & 180 & N/A \\
\hline $\begin{array}{l}\text { Zhou } \\
\text { et al. }{ }^{28}\end{array}$ & $\begin{array}{c}191 \text { hospitalized } \\
\text { patients }\end{array}$ & 6200 & $17 \%$ & 1000 & $40 \%$ & 12.8 & 206 & $7 \%$ \\
\hline $\begin{array}{l}\text { Wang } \\
\text { et al. }{ }^{27}\end{array}$ & $\begin{array}{c}138 \text { hospitalized } \\
\text { patients }\end{array}$ & 4500 & N/A & 800 & $70.3 \%$ & $\mathrm{~N} / \mathrm{A}$ & 163 & $\mathrm{~N} / \mathrm{A}$ \\
\hline $\begin{array}{l}\text { Fan } \\
\text { et al. }{ }^{15}\end{array}$ & $\begin{array}{l}67 \text { hospitalized } \\
\text { patients }\end{array}$ & 4700 & $29.2 \%$ & 1200 & $36.9 \%$ & 14 & 201 & $20 \%$ \\
\hline $\begin{array}{l}\text { Huang } \\
\text { et al. }{ }^{11}\end{array}$ & $\begin{array}{l}41 \text { hospitalized } \\
\text { patients }\end{array}$ & 6200 & $25 \%$ & 800 & $63 \%$ & 12.6 & 164 & $5 \%$ \\
\hline $\begin{array}{l}\text { Young } \\
\text { et al. }{ }^{14}\end{array}$ & $\begin{array}{l}18 \text { hospitalized } \\
\text { patients }\end{array}$ & 4600 & N/A & 1200 & $39 \%$ & 13.5 & 159 & N/A \\
\hline
\end{tabular}

WBC - white blood cell; ALC - absolute lymphocyte count; Hgb - hemoglobin. 
that analyzed the effects of SARS-CoV-2 infection on cell counts have shown similar results. A descriptive case series from Singapore on 18 hospitalized patients reported that $39 \%$ of the patients had lymphopenia. The majority of their patients had a mild form of the disease and $66 \%$ of them did not require supplemental oxygen, which is most likely explained by the low rate of lymphopenia among them. ${ }^{14}$ Another retrospective observational study on 69 patients from the National Center for Infectious Diseases (NCID) in Singapore focused on the hematological parameters of COVID-19 patients. ${ }^{15}$ They observed that $29 \%$ of the patients presented with severe leukopenia (WBC $<2 \times 10^{9} / \mathrm{L}$ ); also, $36.9 \%$ of the patients presented with lymphopenia and 5 out of 25 had severe lymphopenia $\left(\mathrm{ALC}<0.5 \times 10^{9} / \mathrm{L}\right)$. Lymphopenia was more profound in intensive care unit (ICU) patients, with 7 out of 9 being lymphopenic, 4 of whom had severe lymphopenia. In addition, $20 \%$ of their patients had mild thrombocytopenia (platelet count 100-150 × 10\%/L).

Peripheral blood smears obtained from $69 \%$ of the patients showed a few reactive lymphocytes, of which a subset appeared lymphoplasmacytoid. This is contrary to the experience with the SARS-CoV outbreak in 2003, where reactive lymphocytes were not observed in a study from Singapore on hematological parameters and were observed in only $15 \%$ of cases in a study from Hong Kong. ${ }^{16,17}$ Lymphopenia is a well-known feature of SARS-CoV, and was described in patients in Hong Kong and Singapore afflicted with the disease in 2003. It was associated with poor prognosis and ICU stay. ${ }^{16-18}$ Monitoring hematological parameters might help physicians to decide which patients need to be admitted to the ICU. Fan et al. recommended that severe lymphopenia $<0.6 \times 10^{9} / \mathrm{L}$ should be considered as one of the indicators for early admission for supportive care in the ICU. ${ }^{15}$ Their ICU patients also developed more prominent, statistically significant decreases in their hemoglobin levels, absolute lymphocyte count (ALC) and absolute monocyte count (AMC), and increases in absolute neutrophil count (ANC), as compared to the non-ICU group. Fan et al. also performed flow cytometry (FCM) on the peripheral blood of patients in the ICU who had prominent lymphopenia. They found that the ICU patients had significantly lower CD45+, CD3+, CD4+, CD8+, CD19+, and CD16/56+ counts. Inversion of the CD4/CD8 ratio is commonly seen in viral infections such as the human immunodeficiency virus (HIV) and cytomegalovirus (CMV). However, the CD4/CD8 ratio was not inverted in all groups of patients.

Lymphopenia caused by COVID-19 and its detrimental effects on the immune system have been further analyzed. Zheng et al. studied the immunological characteristics of peripheral blood leukocytes from 16 patients in Kunming, China and found that COVID-19 damages the functioning of CD4+ T cells and promotes the excessive activation and possibly the subsequent exhaustion of CD8+ T cells. ${ }^{19}$ A proposed mechanism has been illustrated in Fig. 1. This

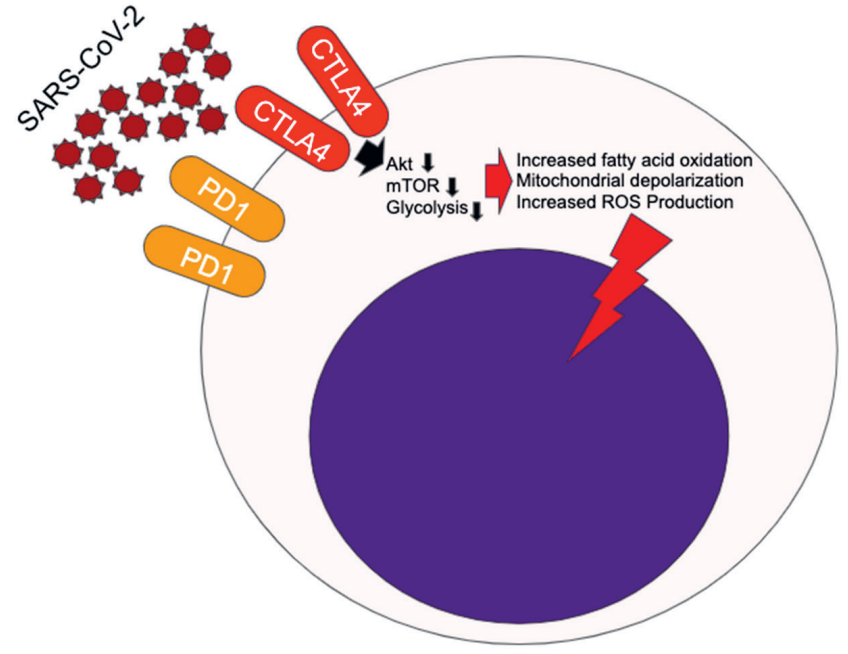

Fig. 1. Exhaustion of CD8+ T cells in SARS-CoV-2 infection. ${ }^{19,20} \mathrm{~T}$ cells express cytotoxic T-lymphocyte-associated protein-4 (CTL4) and programmed cell death protein-1 (PD-1) inhibitory receptors which are activated by chronic infections. PD-1 signaling decreases Akt (protein kinase B) and mammalian target of rapamycin (mTOR) activity, which switches T-cell metabolism from glycolysis to fatty acid oxidation, resulting in mitochondrial depolarization, a higher rate of ROS production and functional impairment of T cells

phenomenon was also previously observed in some chronic infections such as HIV, hepatitis B virus (HBV) and hepatitis $\mathrm{C}$ virus ( $\mathrm{HCV}$ ), as well as in cancer; it can eventually diminish the host's antiviral immunity. ${ }^{20}$ Previous studies indicated that multi-functional $\mathrm{T}$ cells play an important role in immunity against HIV infection and immunity after vaccination. Therefore, functional damage to CD4+ T cells may have predisposed COVID-19 patients to severe disease. ${ }^{21}$ According to Zheng et al., patients with severe SARS-CoV-2 infection had fewer of the non-exhausted (PD-1-negative, cytotoxic T-lymphocyte-associated protein 4 (CTLA-4)-negative and T-cell immunoreceptor with Ig and ITIM domains (TIGIT)-negative CD8+ T cells than the healthy control and mild disease course groups. ${ }^{19}$ For CD8+ T cells, it is beneficial to have a functional blockade of PD-1, CTLA-4 and TIGIT to maintain their antigen-specific immunity and antiviral effects. ${ }^{22,23}$ Therefore, the excessive exhaustion of CD8+ T cells in severe patients may reduce patients' cellular immune response to SARS-CoV-2. A cohort study of 452 patients was performed by Qin et al. in Wuhan, China and showed the dysregulation of immune response in patients with COVID-19. ${ }^{24}$ They found that severe cases had higher leukocyte and neutrophil counts, lower lymphocyte counts, higher neutrophil-to-lymphocyte ratio, and lower percentages of monocytes, eosinophils and basophils. In addition, a lymphocyte subset analysis in 44 patients with COVID-19 revealed a decreased number of B cells, T cells and natural killer (NK) cells, which was more evident in the severe cases $(743.6 / \mu \mathrm{L}$ compared to $1020.1 / \mu \mathrm{L} ; \mathrm{p}=0.032$ ) as compared with the non-severe group. The T-cell counts were found to have decreased to nearly half the lower limit of normal, indicating that $\mathrm{T}$ cells were more affected by SARS-CoV-2, especially 
in severe cases $(461.6 / \mu \mathrm{L}$ compared to $663.8 / \mu \mathrm{L} ; \mathrm{p}=0.027)$. A subset analysis of $\mathrm{T}$ cells showed that both helper $\mathrm{T}(\mathrm{Th})$ cells (CD3+ and CD4+) and suppressor T cells (CD3+ and $\mathrm{CD} 8+$ ) were lower in patients with COVID-19. Based on these findings, they suggested that COVID-19 might be damaging lymphocytes directly and causing immune system dysfunction during acute infection.

Lymphopenia has also been commonly reported (67-75\%) among critically ill patients with COVID-19 in the USA. ${ }^{25,26}$ Other observational studies from Wuhan with 138 and 191 hospitalized patients showed that patients who died from the disease had more severe lymphopenia than survivors, with their lymphocyte counts continuing to decrease until death. ${ }^{27}$ Patients who survived the disease had their lowest lymphocyte counts on day 7 , followed by improvement of their lymphocyte counts during the hospitalization, whereas the patients who had persistently low lymphocyte counts died from the disease. ${ }^{28}$ Thus, monitoring lymphocyte counts might help assess disease severity and progression, and outcomes in patients with COVID-19. Tan et al. created a model based on lymphocyte percentage (LYM\%) for disease classification and prognosis determination. According to their model, patients who have a LYM\% $>20 \%$ on days 10-12 after the onset of symptoms have a good prognosis and recover quickly. In contrast, patients with a LYM\% < 20 on days 10-12 are classified as severe type. At the second point, 17-19 days after symptom onset, patients with a LYM\% $>20 \%$ are likely to recover; patients with $5 \%<$ LYM $\%<20 \%$ are still at risk for decompensation, and patients with a LYM\% < 5\% are considered critically ill and requiring intensive care. ${ }^{29}$ Even though lymphopenia is the most common alteration seen in cell counts and it has very important prognostic significance in COVID-19, there are studies suggesting the use of thrombocytopenia and platelet-lymphocyte ratio (PLR) as a prognostic factor of severe disease.

Thrombocytopenia is commonly seen in critically ill patients in COVID-19. A meta-analysis with 1,779 COVID-19 patients from 9 different studies showed that platelet count was significantly lower in patients with more severe disease (the weighted mean difference of platelet counts: $\left.-31 \times 10^{9} / \mathrm{L} ; 95 \% \mathrm{CI}=-35--29 \times 10^{9} / \mathrm{L}\right) .{ }^{30}$ It has also been shown that low platelet count is associated with a more than five-fold increased risk of severe SARS-CoV-2 infection $(\mathrm{OR}=5.1 ; 95 \% \mathrm{CI}=1.8-14.6)$. Even though its mechanism is not clearly known, it has been suggested that thrombocytopenia might be secondary to endothelial damage from mechanical ventilation and platelet activation, deranged platelet defragmentation from megakaryocytes in the pulmonary vascular bed, and direct bone marrow toxicity as a result of SARS-CoV-2 infection. ${ }^{30,31}$ A singlecenter case series of 30 hospitalized patients diagnosed with COVID-19 showed that patients with a peak in their platelet counts had worse clinical outcomes. ${ }^{32}$ In addition, Platelet-lymphocyte ratio (PLR) value at peak platelet count during treatment was an independent influencing factor for prolonged hospitalization. It was suggested that markedly elevated platelet counts and longer average hospitalization may be related to the cytokine storm.

\section{Hypercoagulable state and acute thrombotic events in COVID-19}

COVID-19 is a novel disease with a very broad spectrum of complications involving different organ systems that are mainly caused by a hypercoagulable state. Patients with severe SARS-CoV-2 infection become prone to develop coagulation abnormalities and acute thrombotic events, but the pathogenesis of hypercoagulopathy in COVID-19 is not completely understood. Direct endothelial injury by SARS-COV-2, immobilization due to severe illness, and a hypercoagulable state caused by increased inflammation and circulating prothrombotic factors are among the reasons why patients with COVID-19 have such a high tendency to develop acute thrombotic events. ${ }^{33-36}$ High d-dimer levels have been reported to be associated with the severe form of disease; as d-dimer is a fibrin degradation product, this indicates thrombin generation and fibrin dissolution. A multicenter retrospective analysis on 1,099 patients from China showed that $46.4 \%$ of patients with SARS-CoV-2 infection had elevated d-dimer levels. ${ }^{10} \mathrm{D}$-dimer elevation was more prominently seen in patients with severe COVID-19 compared to non-severe cases (59.6\% compared with $43.2 \%)$. There are additional studies supporting the evidence that an elevated d-dimer level is associated with adverse outcomes and higher mortality. ${ }^{11,27}$

Panigada et al. studied coagulation parameters and other assays, including von Willebrand factor (VWF) and thromboelastography (TEG), on 24 patients in the ICU who had COVID-19. They also found that the patients were in a hypercoagulable state. ${ }^{35}$ The patients had normal-toincreased platelet counts, near-normal prothrombin time (PT) and activated partial thromboplastin time (aPTT), increased fibrinogen and dramatically increased d-dimer levels, increased factor VIII and VWF levels, decreased antithrombin levels, and increased protein $C$ levels. There are similar studies supporting these findings. ${ }^{36,37}$

Severely ill COVID-19 patients might have similar laboratory findings, with patients suffering from disseminated intravascular coagulation (DIC) who meet the criteria for probable DIC in the scoring system published by the International Society on Thrombosis and Hemostasis (ISTH) in 2009. ${ }^{38}$ However, the majority of acutely ill patients with COVID-19 develop thrombosis rather than bleeding, which later is commonly seen in DIC. As explained previously, patients with COVID-19 have high fibrinogen and factor VIII activity, which suggests that a significant consumption of coagulation factors is not seen as it is in DIC. ${ }^{35-37}$ An observational study 
from the Netherlands including 184 ICU patients evaluated the incidence of acute thrombotic events and none of their patients developed overt DIC. The study reported that $38 \%$ of their patients had coagulopathy (defined as a spontaneous prolongation of PT by $>3 \mathrm{~s}$ or of aPTT by $>5 \mathrm{~s}$ ) on admission and the most common thrombotic complication was pulmonary embolism $(81 \%$ of the thrombotic complications). ${ }^{39}$ Classically, bleeding is seen in acute decompensated DIC due to the rapid consumption of coagulation factors, while thrombosis predominates in chronic compensated DIC. Even though the hypercoagulable state in COVID-19 is similar to compensated DIC, platelet counts and aPTTs are usually normal in COVID-19. ${ }^{35}$

Venous thromboembolism is very common, especially in patients with severe COVID-19. Several autopsy studies on patients who died from COVID-19 showed significant incidence of deep vein thrombosis (DVT; 58\%), pulmonary embolism (PE; 19-42\%) and microthrombi formation in alveolar capillaries (45\%). ${ }^{40,41}$ Widespread thrombosis, microangiopathy and capillary microthrombi, and increased angiogenesis were significantly prominent in lung specimens from patients who had died from COVID-19, and severe endothelial injury was deemed to be the main cause of the hypercoagulable state. ${ }^{42}$ Studies with patients in ICUs reported similar findings. A case series of 829 ICU patients with COVID-19 in New York reported PE in $6.2 \%$ of cases and DVT in $9.4 \% .{ }^{43}$ Other series with fewer patients reported higher VTE rates of 20-43\% even with a prophylaxis dose of anticoagulation, but the rate is as high as $65-69 \%$ in studies that perform routine surveillance with bilateral leg ultrasounds. ${ }^{39,44,45}$ Extracorporeal membrane oxygenation (ECMO) is commonly used in patients with severe hypoxemic respiratory failure secondary to COVID-19 pneumonia. Clotting of the circuit was reported in $16 \%$ of ICU patients in 1 study. ${ }^{37}$ Patients receiving continuous renal replacement therapy (CRRT) in the ICU also were reported to have a strikingly high incidence rate of clotting of the extracorporeal circuit - up to $96 \%$ of cases. ${ }^{37}$ Bilaloglu et al. also studied VTE rates in non-ICU patients and found PE in $2.2 \%$ and DVT in $2 \%$ of 2,505 symptomatic inpatients in New York. ${ }^{43}$ There is a paucity of data on VTE rates on an outpatient basis, which needs to be studied. Arterial thrombosis (stroke, myocardial infarction and limb ischemia) is less commonly seen than venous thrombosis in patients with COVID-19. Stroke was seen in $1.6 \%$ of hospitalized patients and myocardial infarction in $8.9 \% .{ }^{43}$ In an observational cohort of 20 patients with COVID-19 who had acute limb ischemia, it was shown that revascularization was successful in $70 \%$ of cases, but patients had a high mortality rate (40\%). ${ }^{46}$ Hemorrhagic complications are less commonly seen in patients with COVID-19, being reported in $2.7 \%$ of 150 ICU patients, although the bleeding was not spontaneous and it was related to head trauma and anticoagulation. ${ }^{37}$

\section{Inflammatory markers and cytokine storm in COVID-19}

SARS-CoV-2 infection may cause a very broad spectrum of the COVID-19 disease, from asymptomatic (up to 40$45 \%$ of all cases), through mild ( $81 \%$ of the symptomatic cases) and severe (14\% of the symptomatic cases), to lifethreatening infections ( $5 \%$ of the symptomatic cases). ${ }^{6,47}$ Its mean incubation period is 5 days, ranging from 1 to 14 days. ${ }^{48}$ During the incubation period, it can present with fever, malaise, sore throat, diarrhea, and other nonspecific symptoms. ${ }^{10}$ During this period, peripheral blood leukocytes and lymphocytes are usually not significantly reduced..$^{49}$ In the $2^{\text {nd }}$ phase of the disease, usually occurring 7-14 days after the disease onset, the virus can cause viremia which mainly affects the lungs, gastrointestinal tract and heart by binding to ACE- 2 receptors. ${ }^{50}$ In this phase, pneumonia worsens the disease course by causing diffuse bilateral patchy infiltrates in the lungs and potentially causing hypoxemic respiratory failure. As explained previously, lymphocyte counts are significantly lower in severe cases and inflammatory markers (e.g., ferritin, C-reactive protein (CRP), and erythrocyte sedimentation rate), elevated aminotransaminase (ALT/AST) levels and lactate dehydrogenase (LDH) levels can be detected in the blood in high amounts. ${ }^{10}$ Patients might also have markedly elevated levels of interleukins (mostly IL-6, IL-2, IL-7, granulocyte colony stimulating factor, interferon- $\gamma$ inducible protein 10 , monocyte chemoattractant protein-1 (MCP-1), and macrophage inflammatory protein 1-a (MIP1-a) and tumor necrosis factor $\alpha$ (TFN- $\alpha$ ) if they go into a state of "cytokine storm," which may induce lymphocyte apoptosis. ${ }^{51,52} \mathrm{Cy}-$ tokine release syndrome (CRS) or cytokine storm is a type of acute systemic inflammatory reaction classically presenting with fever and multiple organ dysfunction. It commonly occurs secondary to immunotherapies (chimeric antigen receptor T-cell therapy or therapeutic antibodies) and haploidentical allogeneic transplantation. However, severe viral infections such as influenza or SARS-CoV-2 can also cause severe inflammatory response and cytokine storm. ${ }^{53-58}$ Mild cases of CRS are treated with antihistamines, antipyretics and intravenous fluids. Intravenous steroids and tocilizumab (an IL-6 receptor antagonist) can be used for severe cases. ${ }^{55}$

\section{Conclusions}

SARS-CoV-2 is a novel virus which can cause significant changes in blood counts, mainly causing severe lymphopenia and excessive exhaustion of CD8+ T cells in severe cases, which may reduce patients' cellular immune response. When COVID-19 results in viremia in the later course of the disease, it can cause severe inflammatory reactions similar to cytokine storm, which might require ICU admission. In addition, acute thrombotic events are 
commonly seen in patients with severe COVID-19, which makes SARS-COV-2 a unique virus with undiscovered pathophysiology. Patients who are infected with the virus should be evaluated carefully by checking complete blood counts and inflammatory markers as well as further studies to diagnose acute thrombotic events in highrisk or symptomatic cases, both at baseline and during the disease course. Early identification of severe cases and the complications of COVID-19 could decrease the morbidity and mortality rates associated with this disease.

\section{ORCID iDs}

Burak Erdinc (1) https://orcid.org/0000-0003-1065-545X Sonu Sahni (i) https://orcid.org/0000-0001-8766-0703 Vladimir Gotlieb (1) https://orcid.org/0000-0003-2907-3476

\section{References}

1. Zhu N, Zhang D, Wang W, et al. A novel coronavirus from patients with pneumonia in China, 2019. N Engl J Med. 2020;382(8):727-733. doi:10.1056/NEJMoa2001017

2. Johns Hopkins Coronavirus Resource Center. COVID-19 Map. https:// coronavirus.jhu.edu/map.html. Baltimore, MD; John Hopkins University; 2020. Accessed June 28, 2020

3. Su S, Wong G, Shi W, et al. Epidemiology, genetic recombination, and pathogenesis of coronaviruses. Trends Microbiol. 2016;24(6):490-502. doi:10.1016/j.tim.2016.03.003

4. Zhou P, Yang X Lou, Wang XG, et al. A pneumonia outbreak associated with a new coronavirus of probable bat origin. Nature. 2020 579(7798):270-273. doi:10.1038/s41586-020-2012-7

5. He X, Lau EHY, Wu P, et al. Temporal dynamics in viral shedding and transmissibility of COVID-19. Nat Med. 2020;26(5):672-675. doi:10. 1038/s41591-020-0869-5

6. Wu Z, McGoogan JM. Characteristics of and important lessons from the coronavirus disease 2019 (COVID-19) outbreak in China: Summary of a report of 72314 cases from the Chinese Center for Disease Control and Prevention. JAMA. 2020;323(13):1239-1242. doi:10.1001/ jama.2020.2648

7. Drosten C, Günther S, Preiser W, et al. Identification of a novel coronavirus in patients with severe acute respiratory syndrome. $\mathrm{N} \mathrm{Engl}$ J Med. 2003;348(20):1967-1976. doi:10.1056/NEJMoa030747

8. Zhong NS, Zheng BJ, Li YM, et al. Epidemiology and cause of severe acute respiratory syndrome (SARS) in Guangdong, People's Republic of China, in February, 2003. Lancet. 2003;362(9393):1353-1358. doi:10.1016/S0140-6736(03)14630-2

9. Cui J, Li F, Shi ZL. Origin and evolution of pathogenic coronaviruses. Nat Rev Microbiol. 2019;17(3):181-192. doi:10.1038/s41579-018-0118-9

10. Guan W, Ni Z, Hu Y, et al. Clinical characteristics of coronavirus disease 2019 in China. NEngl J Med. 2020;382(18):1708-1720. doi:10.1056/ NEJMoa2002032

11. Huang C, Wang Y, Li X, et al. Clinical features of patients infected with 2019 novel coronavirus in Wuhan, China. Lancet. 2020;395(10223): 497-506. doi:10.1016/S0140-6736(20)30183-5

12. Chen N, Zhou M, Dong X, et al. Epidemiological and clinical characteristics of 99 cases of 2019 novel coronavirus pneumonia in Wuhan, China: A descriptive study. Lancet. 2020;395(10223):507-513. doi:10.1016/S0140-6736(20)30211-7

13. Wu C, Chen X, Cai Y, et al. Risk factors associated with acute respiratory distress syndrome and death in patients with coronavirus disease 2019 pneumonia in Wuhan, China. JAMA Intern Med. 2020;180(7):1-11. doi:10.1001/jamainternmed.2020.0994

14. Young BE, Ong SWX, Kalimuddin S, et al. Epidemiologic features and clinical course of patients infected with SARS-CoV-2 in Singapore. JAMA. 2020;323(15):1488-1494. doi:10.1001/jama.2020.3204

15. Fan BE, Chong VCL, Chan SSW, et al. Hematologic parameters in patients with COVID-19 infection. Am J Hematol. 2020;95(6):E131-E134. doi:10.1002/ajh.25774

16. Chng WJ, Lai HC, Earnest A, Kuperan P. Haematological parameters in severe acute respiratory syndrome. Clin Lab Haematol. 2005;27(1): 15-20. doi:10.1111/j.1365-2257.2004.00652.x
17. Lee $N$, Hui $D$, Wu A, et al. A major outbreak of severe acute respiratory syndrome in Hong Kong. N Eng/J Med. 2003;348(20):1986-1994. doi:10.1056/NEJMoa030685

18. Wong RSM, Wu A, To KF, et al. Haematological manifestations in patients with severe acute respiratory syndrome: Retrospective analysis. BrMed J. 2003;326(7403):1358-1362. doi:10.1136/bmj.326.7403.1358

19. Zheng $H Y$, Zhang $M$, Yang $C X$, et al. Elevated exhaustion levels and reduced functional diversity of $\mathrm{T}$ cells in peripheral blood may predict severe progression in COVID-19 patients. Cell Mol Immunol. 2020; 17(5):541-543. doi:10.1038/s41423-020-0401-3

20. Saeidi A, Zandi K, Cheok YY, et al. T-cell exhaustion in chronic infections: Reversing the state of exhaustion and reinvigorating optimal protective immune responses. Front Immunol. 2018;9:2569. doi:10. 3389/fimmu.2018.02569

21. Van Braeckel E, Desombere I, Clement F, et al. Polyfunctional CD4+ T-cell responses in HIV-1-infected viral controllers compared with those in healthy recipients of an adjuvanted polyprotein HIV-1 vaccine. Vaccine. 2013;31(36):3739-3746. doi:10.1016/j.vaccine.2013.05.021

22. Johnston RJ, Comps-Agrar L, Hackney J, et al. The immunoreceptor TIGIT regulates antitumor and antiviral CD8+ T-cell effector function. Cancer Cell. 2014;26(6):923-937. doi:10.1016/j.ccell.2014.10.018

23. Engeland CE, Grossardt C, Veinalde R, et al. CTLA-4 and PD-L1 checkpoint blockade enhances oncolytic measles virus therapy. Mol Ther. 2014;22(11):1949-1959. doi:10.1038/mt.2014.160

24. Qin C, Zhou L, Hu Z, et al. Dysregulation of immune response in patients with COVID-19 in Wuhan, China. Clin Infect Dis. 2020;71(15): 762-768. doi:10.1093/cid/ciaa248

25. Bhatraju PK, Ghassemieh BJ, Nichols M, et al. COVID-19 in critically ill patients in the Seattle region: Case series. NEng/J Med. 2020;382(21): 2012-2022. doi:10.1056/NEJMoa2004500

26. Arentz M, Yim E, Klaff $L$, et al. Characteristics and outcomes of 21 critically ill patients with COVID-19 in Washington state. JAMA. 2020; 323(16):1612-1614. doi:10.1001/jama.2020.4326

27. Wang D, Hu B, Hu C, et al. Clinical characteristics of 138 hospitalized patients with 2019 novel coronavirus-infected pneumonia in Wuhan, China. JAMA. 2020;323(11):1061-1069. doi:10.1001/jama.2020.1585

28. Zhou F, Yu T, Du R, et al. Clinical course and risk factors for mortality of adult inpatients with COVID-19 in Wuhan, China: A retrospective cohort study. Lancet. 2020;395(10229):1054-1062. doi:10.1016/S01406736(20)30566-3

29. Tan L, Wang $Q$, Zhang $D$, et al. Lymphopenia predicts disease severity of COVID-19: A descriptive and predictive study. Signal Transduct Target Ther. 2020;5(1):33. doi:10.1038/s41392-020-0148-4

30. Lippi G, Plebani M, Henry BM. Thrombocytopenia is associated with severe coronavirus disease 2019 (COVID-19) infections: A meta-analysis. Clin Chim Acta. 2020;506:145-148. doi:10.1016/j.cca.2020.03.022

31. Yang M, Ng MHL, Chi KL. Thrombocytopenia in patients with severe acute respiratory syndrome (review). Hematology. 2005;10(2):101-105. doi:10.1080/10245330400026170

32. Qu R, Ling Y, Zhang Y, et al. Platelet-to-lymphocyte ratio is associated with prognosis in patients with coronavirus disease-19. J Med Virol. 2020;92(9):1533-1541. doi:10.1002/jmv.25767

33. Teuwen LA, Geldhof V, Pasut A, Carmeliet P. COVID-19: The vasculature unleashed. Nat Rev Immunol. 2020;20(7):389-391. doi:10.1038/ s41577-020-0343-0

34. Magro C, Mulvey JJ, Berlin D, et al. Complement associated microvascular injury and thrombosis in the pathogenesis of severe COVID19 infection: A report of five cases. Transl Res. 2020;220:1-13. doi:10. 1016/j.trsl.2020.04.007

35. Panigada M, Bottino N, Tagliabue $P$, et al. Hypercoagulability of COVID-19 patients in intensive care unit: A report of thromboelastography findings and other parameters of hemostasis. $J$ Thromb Haemost. 2020;18(7):1738-1742. doi:10.1111/jth.14850

36. Ranucci M, Ballotta A, Di Dedda U, et al. The procoagulant pattern of patients with COVID-19 acute respiratory distress syndrome. J Thromb Haemost. 2020;18(7):1747-1751. doi:10.1111/jth.14854

37. Helms J, Tacquard C, Severac F, et al. High risk of thrombosis in patients with severe SARS-CoV-2 infection: A multicenter prospective cohort study. Intensive Care Med. 2020;46(6):1089-1098. doi:10.1007/ s00134-020-06062-x

38. Levi M, Toh CH, Thachil J, Watson HG. Guidelines for the diagnosis and management of disseminated intravascular coagulation. BrJHaematol. 2009;145(1):24-33. doi:10.1111/j.1365-2141.2009.07600.x 
39. Klok FA, Kruip MJHA, van der Meer NJM, et al. Incidence of thrombotic complications in critically ill ICU patients with COVID-19. Thromb Res. 2020;191:145-147. doi:10.1016/j.thromres.2020.04.013

40. Menter T, Haslbauer JD, Nienhold R, et al. Post-mortem examination of COVID19 patients reveals diffuse alveolar damage with severe capillary congestion and variegated findings of lungs and other organs suggesting vascular dysfunction. Histopathology. 2020;77(2):198-209. doi:10.1111/his.14134

41. Wichmann D, Sperhake JP, Lütgehetmann M, et al. Autopsy findings and venous thromboembolism in patients with COVID-19. Ann Intern Med. 2020;May 6:M20-2003. doi:10.7326/m20-2003

42. Ackermann M, Verleden SE, Kuehnel M, et al. Pulmonary vascular endothelialitis, thrombosis, and angiogenesis in Covid-19. $N$ Engl J Med. 2020;383(2):120-128. doi:10.1056/nejmoa2015432

43. Bilaloglu S, Aphinyanaphongs Y, Jones S, Iturrate E, Hochman J, Berger JS. Thrombosis in hospitalized patients with COVID-19 in a New York city health system. JAMA. 2020;324(8):799-801. doi:10.1001/ jama.2020.13372

44. Nahum J, Morichau-Beauchant T, Daviaud F, et al. Venous thrombosis among critically ill patients with coronavirus disease 2019 (COVID-19). JAMA Netw Open. 2020;3(5):e2010478. doi:10.1001/jamanetworkopen. 2020.10478

45. Llitjos JF, Leclerc M, Chochois $C$, et al. High incidence of venous thromboembolic events in anticoagulated severe COVID-19 patients. J Thromb Haemost. 2020;18(7):1743-1746. doi:10.1111/jth.14869

46. Bellosta R, Luzzani L, Natalini G, et al. Acute limb ischemia in patients with COVID-19 pneumonia. J Vasc Surg. 2020;72(6):1864-1872. doi:10. 1016/j.jvs.2020.04.483

47. Oran DP, Topol EJ. Prevalence of asymptomatic SARS-CoV-2 infection. Ann Intern Med. 2020;Jun 3:M20-3012. doi:10.7326/m20-3012

48. Li Q, Guan X, Wu P, et al. Early transmission dynamics in Wuhan, China, of novel coronavirus-infected pneumonia. NEngl J Med. 2020; 382(13):1199-1207. doi:10.1056/NEJMoa2001316
49. Li T, Lu H, Zhang W. Clinical observation and management of COVID-19 patients. Emerg Microbes Infect. 2020;9(1):687-690. doi:10.1080/2222 1751.2020 .1741327

50. Xu H, Zhong L, Deng J, et al. High expression of ACE2 receptor of 2019-nCoV on the epithelial cells of oral mucosa. Int J Oral Sci. 2020; 12(1):1-5. doi:10.1038/s41368-020-0074-x

51. Aggarwal S, Gollapudi S, Yel L, Gupta AS, Gupta S. TNF-a-induced apoptosis in neonatal lymphocytes: TNFRp55 expression and downstream pathways of apoptosis. Genes Immun. 2000;1(4):271-279. doi:10.1038/sj.gene.6363674

52. Liao YC, Liang WG, Chen FW, Hsu JH, Yang JJ, Chang MS. IL-19 induces production of IL- 6 and TNF- $a$ and results in cell apoptosis through TNF-a. J Immunol. 2002;169(8):4288-4297. doi:10.4049/jimmunol. 169.8.4288

53. Frey N, Porter D. Cytokine release syndrome with chimeric antigen receptor T-cell therapy. Biol Blood Marrow Transplant. 2019;25(4): e123-e127. doi:10.1016/j.bbmt.2018.12.756

54. Frey NV, Porter DL. Cytokine release syndrome with novel therapeutics for acute lymphoblastic leukemia. Hematology. 2016;2016(1): 567-572. doi:10.1182/asheducation-2016.1.567

55. Abboud R, Keller J, Slade M, et al. Severe cytokine-release syndrome after T-cell-replete peripheral blood haploidentical donor transplantation is associated with poor survival and anti-IL-6 therapy is safe and well-tolerated. Biol Blood Marrow Transplant. 2016;22(10): 1851-1860. doi:10.1016/j.bbmt.2016.06.010

56. Pedersen SF, Ho YC. SARS-CoV-2: A storm is raging. J Clin Invest. 2020; 130(5):2202-2205. doi:10.1172/JCl137647

57. Mehta P, McAuley DF, Brown M, Sanchez E, Tattersall RS, Manson JJ. COVID-19: Consider cytokine storm syndromes and immunosuppression. Lancet. 2020;395(10229):1033-1034. doi:10.1016/S01406736(20)30628-0

58. Liu Q, Zhou YH, Yang ZQ. The cytokine storm of severe influenza and development of immunomodulatory therapy. Cell Mol Immunol. 2016:13(1):3-10. doi:10.1038/cmi.2015.74 